\title{
Stability and inhibitory function of Treg cells under inflammatory conditions in vitro
}

\author{
HUIFANG GUO ${ }^{1}$, LIRU XUN $^{2}$, RUISAN ZHANG ${ }^{1}$, FENGRUI HU $^{1,3}$, JING LUAN $^{1,3}$, \\ KEJING LAO ${ }^{1,3}$, XIAOLONG WANG ${ }^{1}$ and XINGCHUN GOU ${ }^{1,3}$
}

\author{
${ }^{1}$ Shaanxi Key Laboratory of Brain Disorders and School of Basic Medical Science, Xi'an Medical University, \\ Xi'an, Shaanxi 710021; ${ }^{2}$ Nephrology Department of Shaanxi Provincial People's Hospital Affiliated to Xi'an \\ Medical University, Xi'an, Shaanxi 710068; ${ }^{3}$ Institute of Basic and Translational Medicine, \\ Xi'an Medical University, Xi'an, Shaanxi 710021, P.R. China
}

Received January 31, 2019; Accepted May 31, 2019

DOI: $10.3892 /$ etm.2019.7873

\begin{abstract}
Immunotherapy with transplanted T-regulatory (Treg) cells is currently in use. However, patients have complex internal environments with confounding factors, including the presence of inflammatory cytokines. The present study aimed to detect Treg cell function under simulated inflammatory conditions to provide a foundation for Treg cell-based immunotherapy. $\mathrm{CD} 4{ }^{+} \mathrm{CD} 25^{\text {high }}$ Treg cells were sorted from peripheral blood mononuclear cells and cultured for 14 days in the presence of recombinant human interleukin-2 (rhIL-2) and anti-CD3/CD28 beads, with or without $25 \mathrm{ng} / \mathrm{ml}$ rhIL-6. Next, the absolute count of Treg cells was determined, the stability and activity were detected by measuring the expression levels of forkhead box (Fox)P3 and CD39, and the suppressive function of Treg cells was investigated by assessing the suppression of T-effector cell proliferation by Treg cells after co-culture for 5 days. The number of Treg cells cultured in the presence of $25 \mathrm{ng} / \mathrm{ml}$ rhIL- 6 for 14 days was reduced by $49.7 \%$ when compared with that of cells cultured without rhIL-6. Of the Treg cells continually cultured for 14 days without or with $25 \mathrm{ng} / \mathrm{ml}$ rhIL-6, 56.15 and $24.7 \%$ expressed FoxP3, respectively. There was no difference in the activity of the FoxP3 ${ }^{+}$ Treg cells after culture for 14 days without or with $25 \mathrm{ng} / \mathrm{ml}$ rhIL-6. The suppressive function of Treg cells tended to deteriorate in the presence of rhIL-6. In conclusion, IL-6 inhibited the proliferation and stability of Treg cells, suggesting that
\end{abstract}

Correspondence to: Dr Xingchun Gou, Shaanxi Key Laboratory of Brain Disorders and School of Basic Medical Science, Xi'an Medical University, 1 Xinwang Road, Xi'an, Shaanxi 710021, P.R. China E-mail: gouxingchun@189.cn

Mrs. Liru Xun, Nephrology Department of Shaanxi Provincial People's Hospital Affiliated to Xi'an Medical University, 127 Youyi Road (West), Xi'an, Shaanxi 710068, P.R. China

E-mail: xunliru@163.com

Key words: regulatory $\mathrm{T}$ cells, stability, activity, inhibitory function, inflammatory conditions administration of increased numbers of Treg cells may be required during Treg cell-based immunotherapy.

\section{Introduction}

$\mathrm{CD} 4^{+} \mathrm{CD} 25^{+}$forkhead box (Fox)P3 ${ }^{+}$T-regulatory (Treg) cells are an important subset of immune cells that may inhibit the activation, proliferation and cytokine secretion of other types of immune cell. Treg cells have an indispensable role in driving autoimmune tolerance and maintaining the immune balance in vivo (1-3). Abnormal Treg cell functions are widely involved in the occurrence and development of numerous diseases (4-6), and immunotherapy to recover the number and/or function of Treg cells is a good optional treatment for such diseases.

Immunotherapy with transplanted Treg cells has been used in autoimmune diseases and other immune-associated diseases, including type-1 diabetes mellitus, systemic lupus erythematosus (SLE) and graft vs. host disease (GVHD) (7-13) . Culturing sufficient numbers of Treg cells in vitro is the foundation of Treg-based immunotherapy, and maintaining the stable inhibitory function of Treg cells in vivo is pivotal for successful treatment $(8,9)$. However, the stability and inhibitory function of Treg cells in the internal inflammatory environment requires further systematic investigation.

The internal environment of patients with autoimmune diseases is complex and there may be inflammation or elevated levels of inflammatory cytokines, including tumour necrosis factor- $\alpha$, interleukin-1 (IL-1), interleukin-6 (IL-6), interleukin-23 (IL-23) and interferon- $\gamma$ (IFN- $\gamma$ ) expressed in human atherosclerotic plaques $(14,15)$; interleukin-17 (IL-17), IFN- $\gamma$, IL- 6 and IL-23 expressed in type 1 diabetes mellitus (16); IL-1 $\beta$ and IL-17 expressed in SLE (17); and IL-6 expressed in GVHD $(9,18)$. IL-6 is the critical cytokine that mediates inflammation $(18,19)$. As mentioned above, IL-6 is highly expressed in autoimmune diseases and GVHD $(9,14-16,18)$, and the inflammatory environment in vivo may be simulated by adding IL- 6 .

In the present study, the possible inflammatory environment was simulated in vitro by using recombinant human (rh)IL-6 to observe the absolute number, stability, activity and inhibitory function of Treg cells. The present study lays 
a foundation for Treg cell-based immunotherapy in various diseases.

\section{Materials and methods}

Samples. A total of eight healthy blood donors were recruited from Shaanxi Provincial People's Hospital Affiliated to Xi'an Medical University (Xi'an, China); the male/female ratio was $4: 4$, and the average age was $27.8 \pm 1.3$ years. A total of $40 \mathrm{ml}$ sterile peripheral venous blood samples (including heparin to prevent clotting) were collected from all healthy blood donors. The study was approved by the Ethics Committee of Xi'an Medical University (Xi'an, China; approval no. XYLS2019131). According to the principle of informed consent, all healthy blood donors signed consent forms prior to collection of the peripheral blood samples. All of the experiments in this study were performed in accordance with the guidelines for blood sample collection approved by the Institutional Ethics Committee of Xi'an Medical University.

Isolation of peripheral blood mononuclear cells (PBMCs). PBMCs were isolated from the samples via density-gradient centrifugation. First, $20 \mathrm{ml}$ of Lymphoprep ${ }^{\mathrm{TM}}$ (Axis-Shield) was added to each centrifuge tube, and then, $20 \mathrm{ml}$ of the individual peripheral blood sample diluted with an equal volume of PBS was slowly added. After centrifugation for $20 \mathrm{~min}$ at $500 \mathrm{x} g$ under room temperature, the centrifuge tubes were gently removed and the monocyte suspension was isolated and washed with PBS. After the erythrocytes were lysed with FACS lysis solution (BD Biosciences), the isolated PBMCs were washed with PBS and then resuspended in PBS and counted.

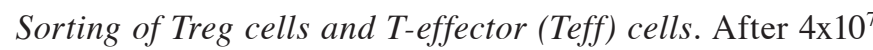
PBMCs were resuspended in RPMI 1640 Media supplemented with $10 \%$ fetal bovine serum and $100 \mathrm{U} / \mathrm{ml}$ penicillin and 100 mg/ml streptomycin (All Gibco; Thermo Fisher Scientific, Inc.), peridinin chlorophyll (PerCP)-conjugated anti-CD4 (cat. no. 347324, BD Biosciences) and allophycocyanine (APC)-conjugated anti-CD25 antibodies (cat. no. 555434, BD Biosciences) were added both at a dilution of 1:5 with the final concentration of PBMCs at $1 \times 10^{6} / 100 \mu 1$. Another $1 \times 10^{6}$ PBMCs were resuspended in media mentioned above, PerCP-conjugated Mouse IgG1 $\kappa$ Isotype Control (cat. nos. 559425, BD Biosciences) and APC-conjugated Mouse IgG1 $\kappa$ Isotype Control (cat. no. 555751, BD Biosciences) were added at a dilution of 1:5 with the final concentration of PBMCs at $1 \times 10^{6} / 100 \mu \mathrm{l}$. After incubation with the antibodies at $4^{\circ} \mathrm{C}$ protected from light for $20 \mathrm{~min}$, the PBMCs were washed with PBS and resuspended in fully supplemented RPMI 1640 Medium. After filtration with a cell strainer (Falcon; BD Biosciences), the stained PBMCs were processed with a BD FACS Aria II (BD Biosciences) and the CD $4{ }^{+} \mathrm{CD} 25^{\text {high }}$ Treg cells and $\mathrm{CD} 4^{+} \mathrm{CD} 25^{-}$Teff cells were sorted. CD25- cells were defined using the isotype control antibody and CD25 $5^{\text {high }}$ cells were defined according to a previous reported protocol (20).

In vitro culture of Treg cells. rhIL-2 and anti-CD3/CD28 beads (Dynabeads ${ }^{\circledR}$ Human T-Expander CD3/CD28 beads; Life Technologies; Thermo Fisher Scientific, Inc.) are necessary for the culturing of Treg cells in vitro, since IL-2 signals are required for the maintenance of lineage stability, survival and suppressor function in mature Tregs, whilst CD3 and CD28 signaling is crucial for the survival and proliferation of Treg cells (21-23). Freshly sorted Treg cells were cultured (1x105/well) in a 96-well U-bottomed plate in the presence of 100,300 or 500 U/ml rhIL-2 (HumanZyme; ProteinTech Group, Inc.) and anti-CD3/CD28 beads (Treg cells/beads ratio, 0.5:1, 1:1 or $2: 1$ ), with or without $25 \mathrm{ng} / \mathrm{ml} \mathrm{rhIL-6} \mathrm{(HumanZyme)}$ under $37^{\circ} \mathrm{C}$ in a humidified atmosphere containing $5 \% \mathrm{CO}_{2}$. The cell concentration was $1 \times 10^{6} / \mathrm{ml}$ and $100 \mu \mathrm{l} /$ well. The Treg cell population was counted after culturing for 3, 5, 7, 10 and 14 days, the medium was replaced after culturing for 3, 5, 7 and 10 days with RPMI 1640 Media supplemented with $10 \%$ fetal bovine serum, $100 \mathrm{U} / \mathrm{ml}$ penicillin, $100 \mathrm{mg} / \mathrm{ml}$ streptomycin and corresponding concentrations of rhIL-2 and rhIL-6.

Stability and activity of Treg cells. Treg cells were collected after culturing for 3, 5, 7, 10 and 14 days. After the cells were washed and resuspended in PBS, PerCP-conjugated anti-CD4 and APC-conjugated anti-CD39 (cat. no. 560239; BD Biosciences) were added at a dilution of 1:5 with final concentration of cells at $1 \times 10^{6} / 100 \mu \mathrm{l}$. The cells were then incubated with the antibodies at $4^{\circ} \mathrm{C}$ while protected from light for $20 \mathrm{~min}$. The cells were then washed twice with PBS and treated for $30 \mathrm{~min}$ with $1 \mathrm{ml}$ fixation/permeabilization buffers and washed three times with $2 \mathrm{ml}$ permeabilization buffer (cat. no. 00-5523-00; Foxp3/transcription factor staining buffer set; eBioscience; Thermo Fisher Scientific, Inc.). Finally, the cells were washed twice with PBS and incubated at $4^{\circ} \mathrm{C}$ in the dark for $30 \mathrm{~min}$ with PE-conjugated anti-FoxP3 antibody (cat. no. 12-4777-42; eBioscience) at a dilution of 1:20. APC-conjugated Mouse IgG2b $\kappa$ Isotype Control (cat. no. 555745; BD Biosciences) were used at a dilution of 1:5 and PE-conjugated Mouse IgG1 kappa Isotype Control (P3.6.2.8.1; cat. no. 12-4714-82; eBioscience) were used at a dilution of 1:20 in the staining procedures. After being washed twice with PBS and filtered using a cell strainer, the stained cells were processed using BD FACSCalibur (BD Biosciences) and the proportions of $\mathrm{CD} 4^{+} \mathrm{FoxP}^{+}$Treg cells and $\mathrm{CD} 39^{+} \mathrm{CD} 4^{+} \mathrm{FoxP} 3^{+}$ active Treg cells were analysed.

Detection of inhibitory function of Treg cells. The inhibitory function of Treg cells was measured by detecting the suppression of Teff cell proliferation in the presence of Treg cells. Freshly sorted Teff cells were labelled with 5,6-carboxyfluorescein succinimidyl ester (CFSE; CellTrace ${ }^{\mathrm{TM}}$ CFSE Cell Proliferation Kit; Invitrogen; Thermo Fisher Scientific, Inc.) according to the manufacturer's protocol. The labelled cells (1x10 $/$ well) were cultured with or without sorted Treg cells $\left(5 \times 10^{4} /\right.$ well) in a 96 -well U-bottomed plate in the presence of anti-CD3/CD28 beads (Teff cells/beads, 1:1), without or with $25 \mathrm{ng} / \mathrm{ml}$ rhIL-6. rhIL-2 was not added, as the Teff cells are able to secrete IL-2 after activation with anti-CD3/CD28 beads (24). The Teff cell proliferation was determined by flow cytometry after Teff cells were cultured for 5 days. The proliferation curves of the Teff cells were fitted, and the Teff-cell proliferation were expressed as the response ( $\mathrm{R}$; the proportion of the precursor sample pool that responded to stimulation by 
A

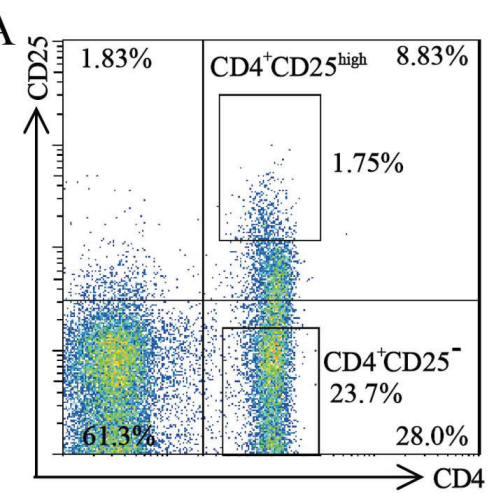

$\mathrm{D}$

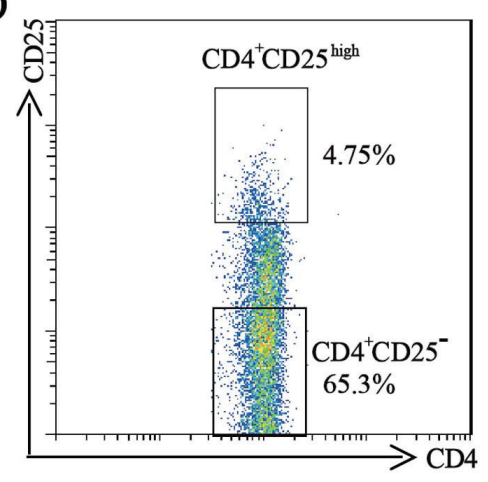

$\mathrm{B}$

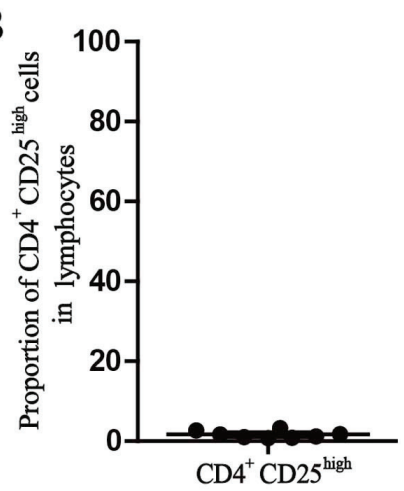

$\mathrm{E}$
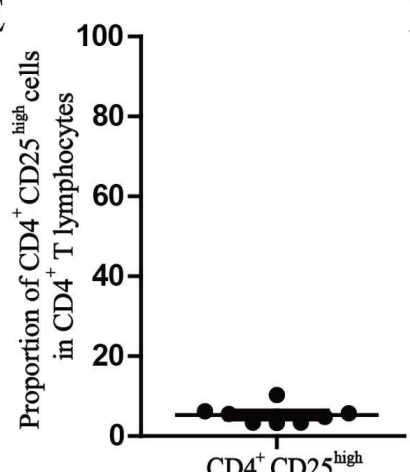

$\mathrm{C}$

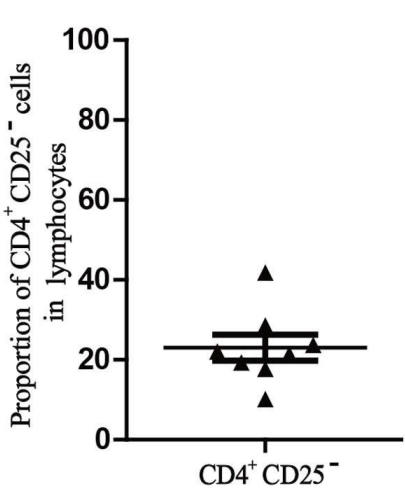

$\mathrm{F}$

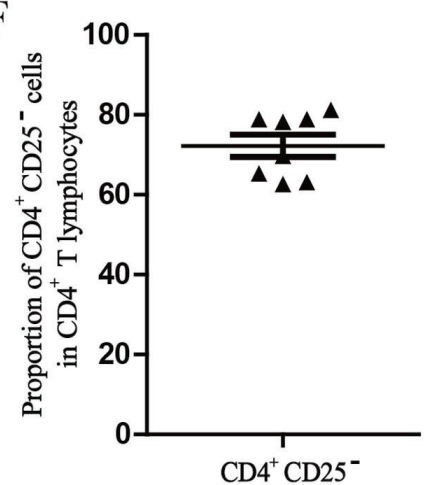

Figure 1. Percentage of CD $4^{+} \mathrm{CD} 25^{\text {high }}$ Treg and CD $4^{+} \mathrm{CD} 25^{-}$effector T cells. (A) Representative dot plots for the percentage of CD4 $4^{+} \mathrm{CD} 25^{\text {high }}$ Treg and $\mathrm{CD} 4^{+} \mathrm{CD} 25^{-}$effector $\mathrm{T}$ cells in the lymphocyte population in PBMCs of a healthy donor. (B) Percentages of CD4 $4^{+} \mathrm{CD} 25^{\text {high }}$ Treg cells in the lymphocyte populations. (C) Percentages of $\mathrm{CD} 4^{+} \mathrm{CD} 25^{-}$effector $\mathrm{T}$ cells in the lymphocyte populations. (D) Representative dot plots for the percentage of CD4 $4^{+} \mathrm{CD} 25^{\text {high }}$ Treg and $\mathrm{CD} 4^{+} \mathrm{CD} 25^{-}$effector $\mathrm{T}$ cells in the $\mathrm{CD} 4^{+} \mathrm{T}$ lymphocyte population in PBMCs from a healthy donor. (E) Percentages of $\mathrm{CD} 4^{+} \mathrm{CD} 25^{\text {high }}$ Treg in the $\mathrm{CD}^{+} \mathrm{T}$ lymphocyte populations in PBMCs of healthy donors. (F) Percentages of $\mathrm{CD}^{+} \mathrm{CD}^{2} 5^{-}$effector $\mathrm{T}$ cells in the CD4 ${ }^{+} \mathrm{T}$ lymphocyte populations in PBMCs from healthy donors. All values are expressed as the mean \pm standard error of the mean $(\mathrm{n}=8)$. PBMCs, peripheral blood mononuclear cells; Treg cells, T-regulatory cells.

dividing), doubling time ( $\mathrm{Td}$; the time required for the average responding $\mathrm{T}$ cell to achieve a single cell division) and the proliferative capacity $(\mathrm{Cp})$ of the responding $\mathrm{T}$ cells in each sample. The methodology for calculating $\mathrm{R}, \mathrm{Td}$ and $\mathrm{Cp}$ from the proliferation curves was described in detail in previous studies (24-26).

Statistical analysis. All flow cytometry results of the present study were analysed with FlowJo software version 7.6.1 (FlowJo LLC). Calculations were performed using GraphPad Prism software, version 6 (GraphPad Software, Inc). Values are expressed as the mean \pm standard error of the mean, the significance of differences between two groups were calculated using paired t-test and Student's unpaired 2-tailed t-te\#st. The significance of differences among three groups was calculated using One-way ANOVA followed by Tukey's test. $\mathrm{P}<0.05$ was considered to indicate a statistically significant difference.

\section{Results}

Sorting of Treg cells and Teff cells. After extracellular staining with PerCP-conjugated anti-CD4 and APC-conjugated anti-CD25, the freshly isolated PBMCs were processed with a BD FACS Aria II to sort the Treg cells and Teff cells (98.0\% purity for each subset). The average proportion of CD $4{ }^{+} \mathrm{CD} 25^{\text {high }}$ Treg cells in the lymphocyte population was $1.7 \pm 0.3 \%$ and the average proportion of $\mathrm{CD} 4{ }^{+} \mathrm{CD} 25^{\text {high }}$
Treg cells in the $\mathrm{CD}^{+}$T-lymphocyte population was $5.3 \pm 0.8 \%$. The average proportion of $\mathrm{CD} 4^{+} \mathrm{CD} 25^{-}$Treg cells in the lymphocyte population was $23.1 \pm 3.3 \%$ and the average proportion of $\mathrm{CD} 4{ }^{+} \mathrm{CD} 25^{\text {high }}$ Treg cells in the $\mathrm{CD} 4^{+}$ T-lymphocyte population was $72.2 \pm 2.8 \%$ (Fig. 1).

Optimum concentration of rhIL-2 and anti-CD3/CD28 beads for culture of Treg cells. The absolute counts of Treg cells cultured with 100,300 or $500 \mathrm{U} / \mathrm{ml}$ rhIL-2 for 14 days in the presence of anti-CD3/CD28 beads (Treg cells/beads, 1:1) in vitro are presented in Fig. 2A. The number of Treg cells was $1 \times 10^{5} /$ well on day 0 , except for the experiment for detection of inhibitory function. The number of Treg cells increased steadily until reaching a plateau $\sim$ day 10 after culturing in vitro. There were no differences among the counts of Treg cells cultured with 100,300 or $500 \mathrm{U} / \mathrm{ml}$ rhIL-2 for 3 or 5 days. There was a significant difference between the counts of Treg cells cultured with 100 and $300 \mathrm{U} / \mathrm{ml}$ rhIL-2 for 7,10 or 14 days. There was no difference between the counts of Treg cells cultured with 300 and $500 \mathrm{U} / \mathrm{ml}$ rhIL-2 for 7,10 or 14 days.

The absolute counts of the Treg cells cultured for 14 days with anti-CD3/CD28 beads (Treg cells/beads, $0.5: 1,1: 1$ or 2:1) in the presence of $300 \mathrm{U} / \mathrm{ml}$ rhIL-2 in vitro are presented in Fig. 2B. The Treg cell counts also increased with culture time until plateauing $\sim$ day 10 . There were no differences among the counts of Treg cells cultured in vitro, whether the ratio 
A
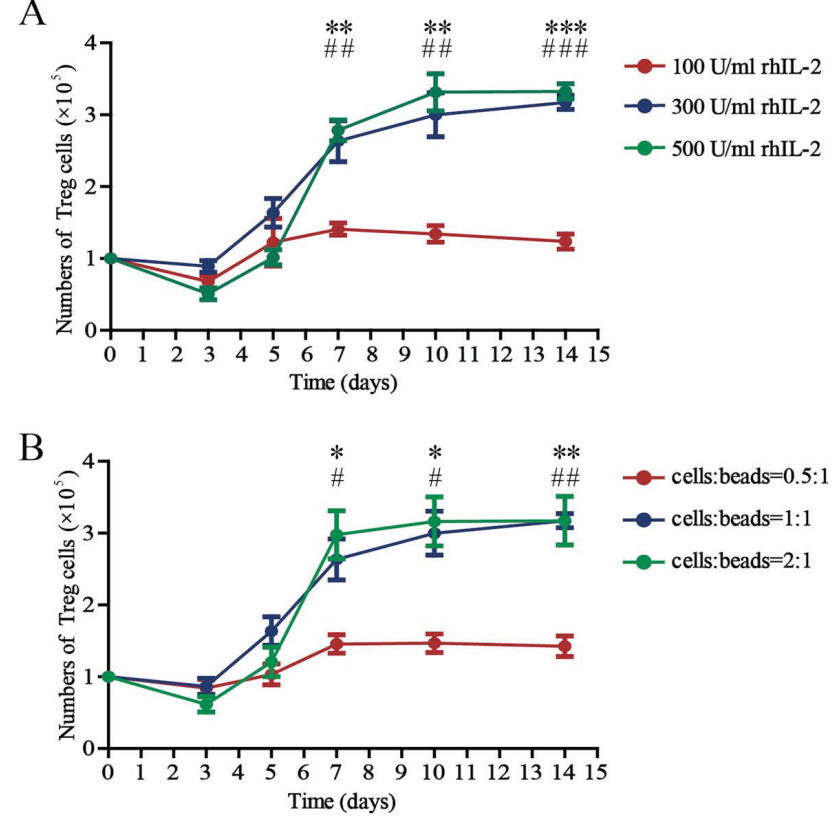

Figure 2. Number of Treg cells cultured in the presence of different concentrations of rhIL-2 and anti-CD3/CD28 beads. (A) Number of all Treg cells after 3, 5, 7, 10 and 14 days of culture in the presence of anti-CD3/CD28 beads (Treg cells/beads, 1:1) and rhIL-2 (100, 300 or $500 \mathrm{U} / \mathrm{ml})$. Values are expressed as the mean \pm standard error of the mean $(n=8)$. ${ }^{* * *} \mathrm{P}<0.01$ and ${ }^{* * * *} \mathrm{P}<0.0001,100$ vs. $300 \mathrm{U} / \mathrm{ml}$ rhIL-2 on the indicated days and ${ }^{\# \#} \mathrm{P}<0.01$ and

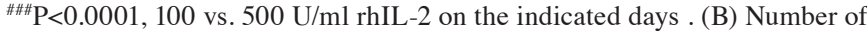
all Treg cells after 3,5,7,10 and 14 days of culture in the presence of rhIL-2 (300 U/ml) and anti-CD3/CD28 beads (Treg cells/beads, $0.5: 1,1: 1$ or 2:1). Values are expressed as the mean \pm standard error of the mean $(\mathrm{n}=8)$. ${ }^{*} \mathrm{P}<0.05$ and ${ }^{* *} \mathrm{P}<0.01$, cells:beads $0.5: 1$ vs. $1: 1$ on the indicated days and ${ }^{*} \mathrm{P}<0.05$ and ${ }^{\# \#} \mathrm{P}<0.01$, cells/beads $0.5: 1$ vs. $2: 1$ on the indicated days. rhIL, recombinant human interleukin; Treg cells, T-regulatory cells.

of cells to beads was $0.5: 1,1: 1$ or 2:1 during culture for 3 or 5 days. There was a significant difference between the counts of Treg cells cultured with beads at a $0.5: 1$ cell-to-bead ratio and those cultured with beads at a 1:1 cell-to-bead ratio at 7 , 10 or 14 days. There was no difference in the counts between Treg cells cultured with beads at a 1:1 ratio and those cultured with beads at a 2:1 ratio at 7,10 or 14 days.

The above results demonstrate that the absolute count of the Treg cells is significantly affected by the concentration of rhIL-2 and anti-CD3/CD28 beads; $300 \mathrm{U} / \mathrm{ml}$ rhIL-2 and a 1:1 cell/bead ratio are the optimal concentrations when the Treg cells are cultured in vitro, and $3.17 \pm 0.10 \times 10^{5}$ cells were obtained after 14 days of culture.

The Treg cell number is reduced under inflammatory conditions. The absolute counts of Treg cells cultured for 14 days in the presence of rhIL-2 $(300 \mathrm{U} / \mathrm{ml})$ and anti-CD3/CD28 beads (Treg cells/beads, 1:1), without or with $25 \mathrm{ng} / \mathrm{ml}$ rhIL-6 in vitro are presented in Fig. 3. There was no difference in the counts of Treg cells cultured without and with $25 \mathrm{ng} / \mathrm{ml}$ rhIL-6 when cultured for $<5$ days in vitro. There was a significant difference in the counts of Treg cells cultured without and with $25 \mathrm{ng} / \mathrm{ml}$ rhIL-6 when cultured for $>7$ days $(\mathrm{P}<0.05)$. The number of Treg cells cultured in the presence of $25 \mathrm{ng} / \mathrm{ml}$ rhIL- 6 for 14 days was reduced by $49.7 \%$ when compared with that of cells cultured without rhIL-6.

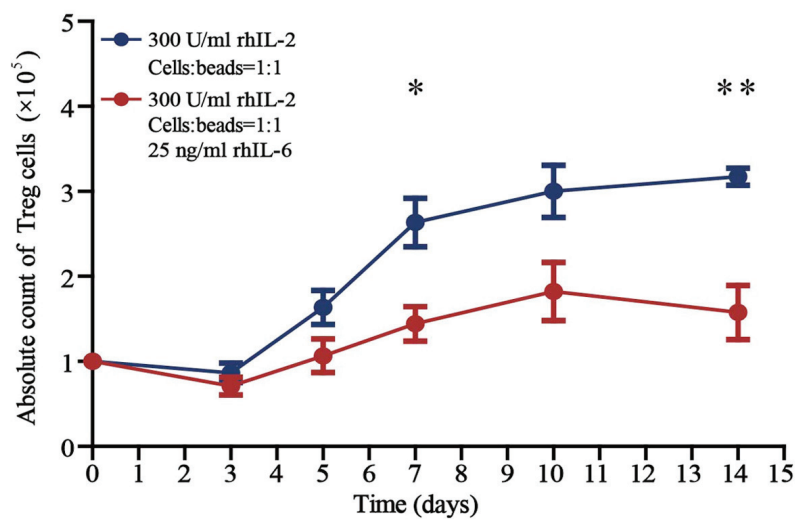

Figure 3. Number of Treg cells following treatment with or without rhIL-6. Number of all Treg cells after culture for 3, 5, 7, 10 and 14 days in the presence of rhIL-2 (300 U/ml) and anti-CD3/CD28 beads (Treg cells/beads, 1:1) $(\mathrm{n}=8)$, without or with $25 \mathrm{ng} / \mathrm{ml}$ rhIL-6. Unpaired Student's t-test was used to compare differences between groups without and with rhIL-6. Values are expressed as the mean \pm standard error of the mean $(n=8)$. ${ }^{*} \mathrm{P}<0.05$, Treg cells cultured for 7 days without vs. with rhIL-6 and ${ }^{* *} \mathrm{P}<0.01$, Treg cells cultured for 14 days without vs. with rhIL-6. rhIL, recombinant human interleukin; Treg cells, T-regulatory cells.

The stability of Treg cells declines under inflammatory conditions. Treg cells were cultured $(300 \mathrm{U} / \mathrm{ml} \mathrm{rhIL}-2$; Treg cells/beads, 1:1; without or with $25 \mathrm{ng} / \mathrm{ml} \mathrm{rhIL}-6$ ) for 14 days in vitro; the proportion of $\mathrm{CD}^{+}{ }^{+} \mathrm{Fox} \mathrm{P}^{+}$Treg cells within the total cell population of the well (thereafter referred to as total cell population) and the FoxP3 mean fluorescence intensity (MFI) of $\mathrm{CD} 4{ }^{+} \mathrm{FoxP}^{+}$Treg cells are presented in Fig. 4A and B, respectively. The proportion of $\mathrm{CD}^{+}{ }^{+} \mathrm{FoxP} 3^{+}$Treg cells was $98.0 \%$ on day 0 , as the purity for sorted Treg cells was $98.0 \%$. Regarding the proportion of $\mathrm{CD} 4^{+} \mathrm{FoxP} 3^{+}$Treg cells within the total cell population, there was a significant difference in the proportion of $\mathrm{CD}^{+}{ }^{+} \mathrm{FoxP}^{+}{ }^{+}$Treg cells cultured without and with $25 \mathrm{ng} / \mathrm{ml}$ rhIL-6 when cultured for 3, 5, 7, 10 and 14 days $(\mathrm{P}<0.05)$. In terms of the FoxP3 MFI of $\mathrm{CD}^{+}{ }^{+} \mathrm{FoxP}{ }^{+}$Treg cells, there was no difference between the cells cultured without and with $25 \mathrm{ng} / \mathrm{ml} \mathrm{rhIL}-6$, whether cultured for $3,5,7,10$ or 14 days in vitro.

Regarding the proportion of $\mathrm{CD} 4{ }^{+} \mathrm{FoxP}_{3}{ }^{+}$cells within the total cell population cultured in the presence of rhIL-2, which gradually declined over the 14-day culture period, the proportion of Treg cells cultured with rhIL-6 decreased much faster compared with the proportion of Treg cells cultured without rhIL-6 (Fig. 4A). Among the Treg cells cultured without rhIL-6, there were always certain amounts of cells expressing FoxP3, although the proportion declined gradually, and the proportion of $\mathrm{CD} 4{ }^{+} \mathrm{FoxP} 3^{+}$Treg cells within the total cell population was $56.2 \pm 2.7 \%$ after Treg cells were cultured for 14 days. However, FoxP3 expression decreased more rapidly in the Treg cells cultured with rhIL-6, and the proportion of $\mathrm{CD}^{+}{ }^{+} \mathrm{FoxP}^{+}$Treg cells within the total cell population was $24.7 \pm 3.4 \%$ after Treg cells were cultured for 14 days, which suggests a lower stability of Treg cells in the inflammatory environment and that increased numbers of Treg cells should be used in treatments considering the complexity of the internal environments of patients. 

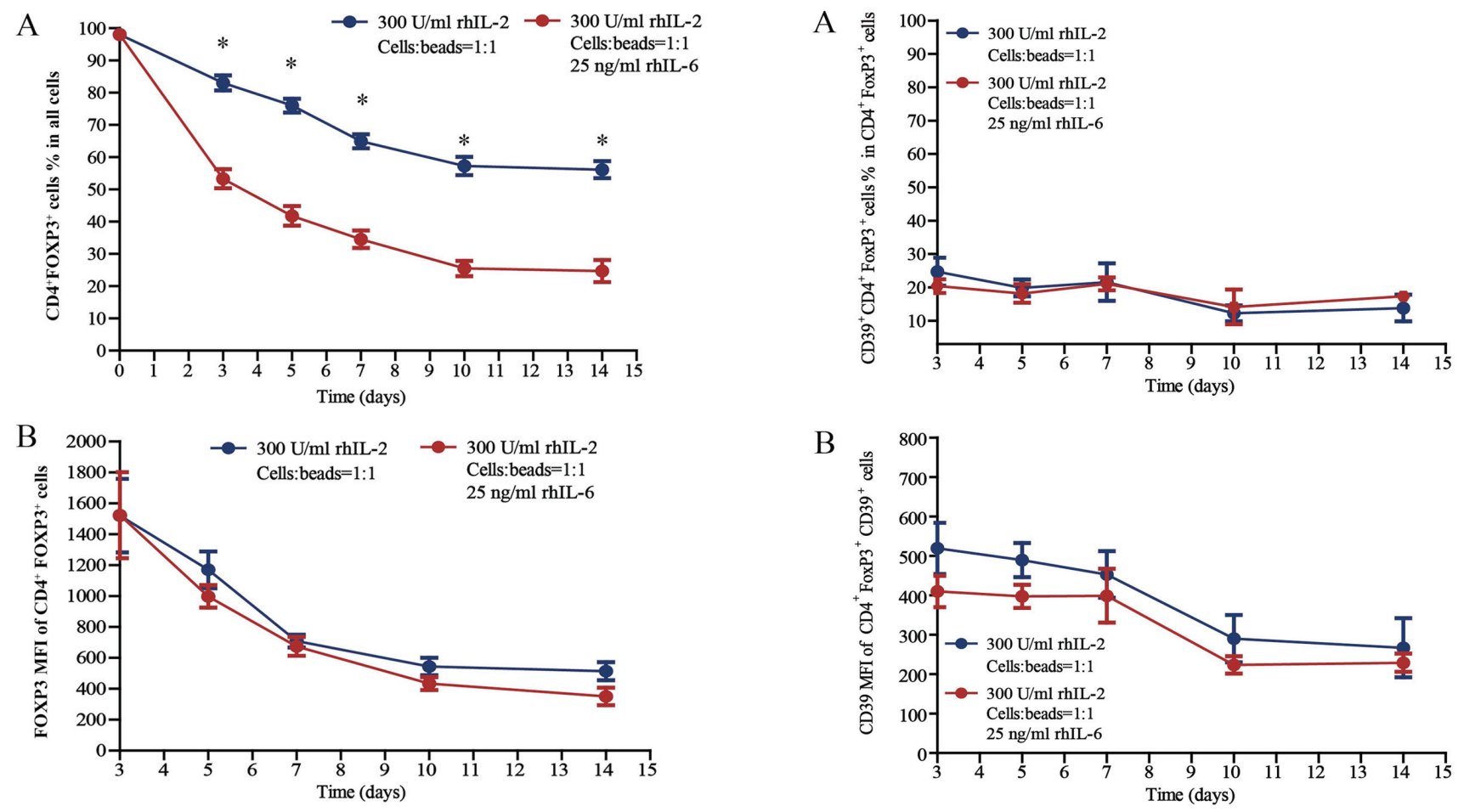

Figure 4. Proportion of $\mathrm{CD}^{+}{ }^{+} \mathrm{FoxP} 3^{+}$Treg cells in all cell populations under inflammatory conditions. Percentages of $\mathrm{CD} 4^{+} \mathrm{FoxP} 3^{+}$Treg cells among (A) all cell populations and (B) the FoxP3 MFI of $\mathrm{CD}^{+}{ }^{+} \mathrm{FoxP}^{+}$Treg cells after culture for 3, 5, 7, 10 and 14 days in the presence of rhIL-2 $(300 \mathrm{U} / \mathrm{ml})$ and anti-CD3/CD28 beads (Treg cells/beads, 1:1), with or without $25 \mathrm{ng} / \mathrm{ml}$ rhIL-6. Unpaired Student's t-test was used to compare differences between groups without and with rhIL-6. Values are expressed as the mean \pm standard error of the mean $(n=8)$. "P<0.05 vs. Treg cells cultured with rhIL-6. MFI, mean fluorescence intensity; Treg cells, T-regulatory cells; FoxP3, forkhead box P3; rhIL, recombinant human interleukin.

The activity of Treg cells remains unchanged under inflammatory conditions. The activity of Treg cells was then investigated by detecting CD39 expression, as the expression of CD39 on T cells reflects high activity (27). The proportions of $\mathrm{CD} 39^{+} \mathrm{CD} 4{ }^{+} \mathrm{FoxP}^{+}$active Treg cells in the $\mathrm{CD}^{+}{ }^{+} \mathrm{FoxP} 3^{+}$cell population after culture for $3,5,7,10$ or 14 days in the presence of rhIL-2 $(300 \mathrm{U} / \mathrm{ml})$ and anti-CD3/CD28 beads (Treg cells/beads, 1:1), without or with $25 \mathrm{ng} / \mathrm{ml}$ rhIL-6, are provided in Fig. 5. Regarding the proportion of $\mathrm{CD}^{3} 9^{+} \mathrm{CD} 4^{+} \mathrm{FoxP} 3^{+}$ Treg cells in the $\mathrm{CD} 4^{+} \mathrm{FoxP}^{+}$cell population and the $\mathrm{CD} 39$ MFI of CD $39^{+} \mathrm{CD}^{+}{ }^{+} \mathrm{FoxP}^{+}{ }^{+}$Treg cells, there was no difference between the cells cultured without rhIL-6 and with $25 \mathrm{ng} / \mathrm{ml}$ rhIL-6, whether cultured for 3, 5, 7, 10 or 14 days in vitro.

The proportion of active Treg cells in the $\mathrm{CD}^{+}{ }^{+} \mathrm{FoxP}^{+}$cell population remained unchanged during the 14 days of culture in vitro, even under inflammatory conditions, which further proves the stability of the Treg-cell subset and provides a basis for the clinical application of Treg cells.

The inhibitory function of Treg cells declines under inflammatory conditions. Finally, the suppressive function of Treg cells cultured without or with $25 \mathrm{ng} / \mathrm{ml}$ rhIL- 6 was investigated by measuring their ability to suppress the Teff cell proliferation in vitro. After Treg and Teff cells were sorted from the PBMCs of healthy donors $(n=8)$, the Teff cells were labelled with CFSE and co-cultured with Treg cells (Teff cells/Treg cells, 2:1) in

Figure 5. Proportion of $\mathrm{CD} 39^{+} \mathrm{CD} 4^{+} \mathrm{FoxP} 3^{+}$active Treg cells in the $\mathrm{CD}^{+}{ }^{+} \mathrm{FoxP}^{+}$cell populations. Percentages of $\mathrm{CD} 39^{+} \mathrm{CD} 4^{+} \mathrm{FoxP} 3^{+}$active Treg cells among (A) the $\mathrm{CD}^{+}{ }^{+} \mathrm{FoxP}^{+}$Treg cells and (B) the CD39 MFI of $\mathrm{CD} 39^{+} \mathrm{CD} 4^{+} \mathrm{FoxP} 3^{+}$Treg cells after culture for 3, 5, 7, 10 and 14 days in the presence of rhIL-2 $(300 \mathrm{U} / \mathrm{ml})$ and anti-CD3/CD28 beads (Treg cells/beads, 1:1), with or without $25 \mathrm{ng} / \mathrm{ml} \mathrm{rhIL}-6$. Unpaired Student's t-test was used to compare differences between groups without and with rhIL-6. Values are expressed as the mean \pm standard error of the mean $(n=8)$. There was no statically significant differences were observed between the CD39 expression of the Treg cells between the two groups $(\mathrm{P}>0.05)$. MFI, mean fluorescence intensity; Treg cells, T-regulatory cells; FoxP3, forkhead box P3; rhIL, recombinant human interleukin.

the presence of anti-CD3/CD8 beads (Teff cells/beads, 1:1), without or with $25 \mathrm{ng} / \mathrm{ml}$ rhIL-6. Teff-cell proliferation was detected after culture for 5 days by gating on $\mathrm{CFSE}^{+}$cells, and the results of the corresponding $\mathrm{R}, \mathrm{Td}$, and $\mathrm{Cp}$ measurements were presented in Fig. 6 (24-26).

The representative overlaid proliferation curve comparing Teff cells cultured alone and Teff cells co-cultured with Treg cells are presented in Fig. 6A, the proliferation of Teff cells was inhibited when co-cultured with Treg cells, independent of rhIL-6 presence (Fig. 6A). As presented in Fig. 6B, the proportion of the precursor sample pool that responded to stimulation by dividing (R-value) did not change significantly when the Teff cells were co-cultured with Treg cells, regardless of rhIL-6 presence. In terms of the time required for the average responding $\mathrm{T}$ cell to achieve a single cell division the (Td value) shown in Fig. 6C, co-culture of Teff cells with Treg cells led to a significantly prolonged $\mathrm{Td}(\mathrm{P}<0.05)$ in a manner that was independent of rhIL-6 presence. Regarding the proliferative capacity (Cp value) showed in Fig. 6D, co-culture with Treg cells led to a significantly decreased $\mathrm{Cp}(\mathrm{P}<0.05)$ independent of rhIL-6 presence.

These results demonstrated that Treg cells exert suppressive effects on Teff cells in the presence or absence of rhIL-6. 
A

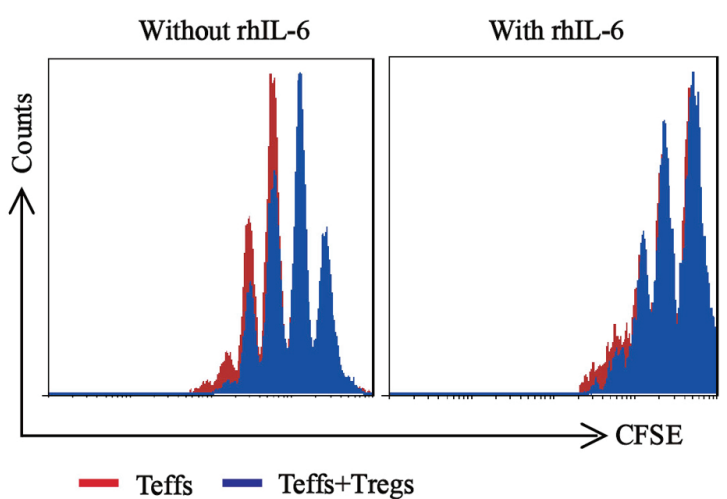

$\mathrm{C}$

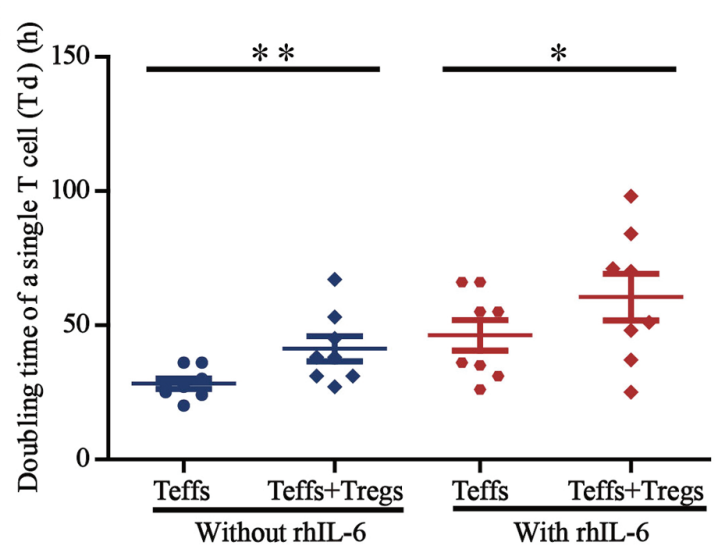

$\mathrm{B}$

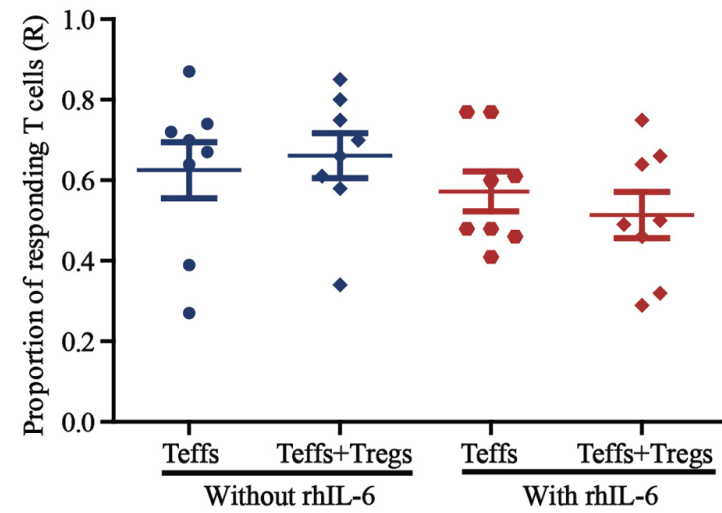

D

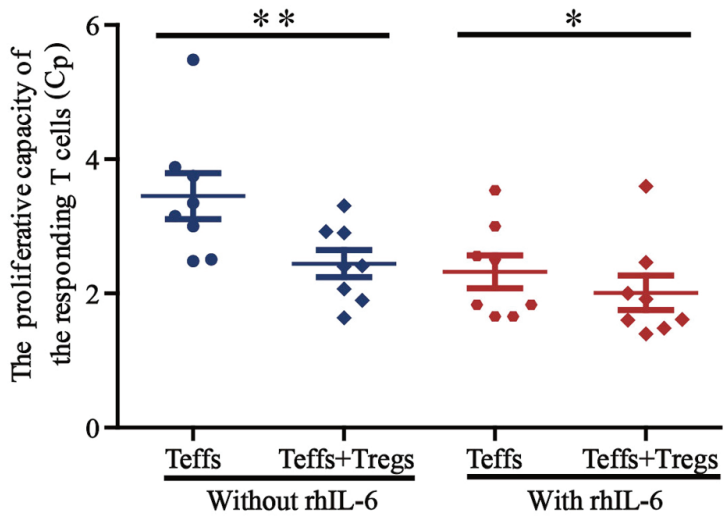

Figure 6. Suppression of Treg cells under inflammatory conditions. (A) Representative histograms indicating the CFSE dilution from a sample cultured without rhIL-6 and a sample cultured with $25 \mathrm{ng} / \mathrm{ml}$ rhIL-6. The proliferation curve of Teff cells cultured alone (red) was overlaid with the curve for Teff cells co-cultured with Treg cells (blue). (B-D) The sorted Teff cells from healthy blood donors ( $\mathrm{n}=8$ ) were labelled with CFSE and co-cultured with sorted Treg cells (Teff cells/Treg cells, 2:1) in the presence of anti-CD3/CD28 beads (Teff cells/beads, 1:1), without or with 25 ng/ml rhIL-6. After co-culture for 5 days, Teff-cell proliferation was assessed by flow cytometry, and (B) the proportion of responding T-cells, (C) doubling time of a single T-cell and (D) proliferative capacity for the Teff cells were calculated. Paired Student's t-test was used to compare differences between groups without and with rhIL-6. Values are expressed as the mean \pm standard error of the mean $(n=8)$. ${ }^{*} \mathrm{P}<0.05$ and ${ }^{* *} \mathrm{P}<0.01$ compared the doubling time of a single $\mathrm{T}$-cell and proliferative capacity of Teff cells cultured for 5 days without vs. with Treg cells. Treg cells, T-regulatory cells; Teff cells, T effector cells; CFSE, 5,6-carboxyfluorescein succinimidyl ester; rhIL, recombinant human interleukin.

However, the inhibitory function of Treg cells may weaken in the presence of rhIL-6, which further suggests that increased numbers of Treg cells should be used for treatment considering the complexity of the internal environment of the patient.

\section{Discussion}

As an important inhibitory immune cell subset in vivo, Treg cells have great potential in the immunotherapy of various diseases, including autoimmune diseases (7-10). Considering the complex internal environment of patients, e.g. inflammatory conditions, the stability and inhibitory function of Treg cells under such conditions should be further investigated.

Transplanting a sufficiently large number of Treg cells is a key factor for successful immunotherapy of diseases, including autoimmune diseases. Although Treg cells may be easily cultured and amplified in vitro in the presence of IL-2 and anti-CD3/CD8 beads $(19,23,28,29)$, the survival of Treg cells may be affected by inflammatory cytokines, including IL-6, in vivo (30-33). In the present study, the number of Treg cells cultured in the presence of $25 \mathrm{ng} / \mathrm{ml} \mathrm{rhIL-} 6$ for 14 days was reduced by $49.7 \%$ when compared with that of cells cultured without rhIL-6, demonstrating the influence of the environment on Treg cell survival. Therefore, an increased number of Treg cells may be required for immunotherapy in patients with autoimmune diseases.

A sufficient number of Treg cells is the foundation of immunotherapy; more importantly, the stability and activity of Treg cells are directly associated with the effectiveness of treatment (34). In the present study, 56.0 or $24.7 \%$ of Treg cells expressed the transcription factor FoxP3 after in vitro culture for 14 days without or with rhIL-6, respectively. These results indicate that Treg cells are a relatively stable cell subset, but their stability declined significantly under inflammatory conditions, further suggesting that for immunotherapy, transplantation of increased numbers of Treg cells is required.

The expression of CD39 on the Treg cell membrane suggests increased activity of Treg cells $(25,35)$. In the present study, the proportion of CD39 expressed by FoxP3 ${ }^{+}$Treg cells did not change with culture time, even in the presence of the inflammatory cytokine rhIL-6. These results suggest that FoxP $3^{+}$Treg cells may maintain their activity in an inflammatory environment. This result is also consistent with that 
of a previous study, which indicated that CD $39^{+}$Treg cells have a strong suppressive function even in the presence of inflammatory cytokines in vitro (36).

Suppression of Teff cell proliferation is an important aspect of the inhibitory function of Treg cells. In the present study, Treg cells suppressed the proliferation of Teff cells, which is consistent with the previous results regarding the stability and activity of Treg cells cultured for 5 days. A decreasing trend regarding Treg cell suppression was observed in the presence of rhIL-6. The inhibitory function of Treg cells is directly linked to the treatment effect of Treg cell-based immunotherapy.

The present study systematically examined the absolute count, stability, activity and inhibitory function of Treg cells, and possible changes in Treg cell function in the presence of cytokines that simulate inflammatory environments were determined in vivo. To achieve good efficacy, transplantation of increased numbers of Treg cells may be a reasonable therapeutic approach for immunotherapy. The present study provides an important experimental basis for the development of Treg cell-based immunotherapy for various immune-associated diseases, including autoimmune diseases.

\section{Acknowledgements}

The authors would like to thank The Youth Innovation Team of Shaanxi Universities for their support.

\section{Funding}

The present study was supported by the National Natural Science Foundation of China (grant no. 81471415), the Natural Science Basic Research Plan in Shaanxi Province of China (program no. 2018JQ8043 and 2018ZDXM-SF-040), the Scientific Research Fund of Shaanxi Provincial Education Department (grant no. 18JS104) and the Research Foundation of Xi'an Medical University (grant nos. 12FZ28, 2017DOC14, 2017GJFY30 and 2016DOC28).

\section{Availability of data and materials}

All data generated or analyzed during the present study are included in this published article.

\section{Authors' contributions}

$\mathrm{HG}, \mathrm{LX}$ and XG conceived the project and designed the present study. HG, RZ, FH and JL performed the experiments, data analysis and wrote the manuscript. $\mathrm{HG}, \mathrm{XW}$ and $\mathrm{KL}$ performed data analysis and revised the manuscript. LX and XG supervised the work, provided administrative support, performed data analysis and proofread the paper.

\section{Ethics approval and consent to participate}

The study was approved by the Ethics Committee of Xi'an Medical University (Xi'an, China). According to the principles of informed consent, all healthy blood donors provided this prior to collection of peripheral blood samples. All of the experiments of the present study were performed in accordance with the relevant guidelines and regulations.

\section{Patient consent for publication}

Not applicable.

\section{Competing interests}

The authors declare that they have no competing interests.

\section{References}

1. Togashi Y and Nishikawa H: Regulatory T cells: Molecular and cellular basis for immunoregulation. Curr Top Microbiol Immunol 410: 3-27, 2017.

2. Vignali DA, Collison LW and Workman CJ: How regulatory T cells work. Nat Rev Immunol 8: 523-532, 2008.

3. Collison LW, Chaturvedi V, Henderson AL, Giacomin PR, Guy C, Bankoti J, Finkelstein D, Forbes K, Workman CJ, Brown SA, et al: IL-35-mediated induction of a potent regulatory T cell population. Nat Immunol 11: 1093-1101, 2010.

4. Guo H, Xun L, Zhang R and Gou X: Ratio of CD $147^{\text {high }} / \mathrm{CD} 147^{\text {low }}$ in $\mathrm{CD}^{+}{ }^{+} \mathrm{CD} 25^{+} \mathrm{T}$ cells: A potential biomarker for early diagnosis and prediction of response to therapy for autoimmune diseases. Med Hypotheses 115: 1-4, 2018.

5. Talaat RM, Mohamed SF, Bassyouni IH and Raouf AA: Th1/Th2/Th17/Treg cytokine imbalance in systemic lupus erythematosus (SLE) patients: Correlation with disease activity. Cytokine 72: 146-153, 2015.

6. Bluestone JA, Buckner JH, Fitch M, Gitelman SE, Gupta S, Hellerstein MK, Herold KC, Lares A, Lee MR, Li K, et al: Type 1 diabetes immunotherapy using polyclonal regulatory T cells. Sci Transl Med 7: 315ra189, 2015.

7. Ou HX, Guo BB, Liu Q, Li YK, Yang Z, Feng WJ and Mo ZC: Regulatory $T$ cells as a new therapeutic target for atherosclerosis. Acta Pharmacol Sin 39: 1249-1258, 2018.

8. Martin-Moreno PL, Tripathi S and Chandraker A: Regulatory $\mathrm{T}$ cells and kidney transplantation. Clin J Am Soc Nephrol 13: 1760-1764, 2018

9. Qiu R, Zhou L, Ma Y, Zhou L, Liang T, Shi L, Long J and Yuan D: Regulatory T cell plasticity and stability and autoimmune diseases. Clin Rev Allergy Immunol Nov 17, 2018 (Epub ahead of print).

10. Alvarez C, Rojas C, Rojas L, Cafferata EA, Monasterio G and Vernal R: Regulatory T lymphocytes in periodontitis: A translational view. Mediators Inflamm 2018: 7806912, 2018.

11. Sakaguchi S, Sakaguchi N, Asano M, Itoh M and Toda M: Pillars article: Immunologic self-tolerance maintained by activated T cells expressing IL-2 receptor $\alpha$-chains (CD25). Breakdown of a single mechanism of self-tolerance causes various autoimmune diseases. J. Immunol. 1995. J Immunol 186: 3808-3821, 2011.

12. Jeffery HC, Braitch MK, Brown S and Oo YH: Clinical potential of regulatory $\mathrm{T}$ cell therapy in liver diseases: An overview and current perspectives. Front Immunol 7: 334, 2016.

13. Lam AJ, Hoeppli RE and Levings MK: Harnessing advances in $\mathrm{T}$ regulatory cell biology for cellular therapy in transplantation. Transplantation 101: 2277-2287, 2017.

14. Ait-Oufella H, Taleb S, Mallat Z and Tedgui A: Recent advances on the role of cytokines in atherosclerosis. Arterioscler Thromb Vasc Biol 31: 969-979, 2011.

15. Fatkhullina AR, Peshkova IO and Koltsova EK: The role of cytokines in the development of atherosclerosis. Biochemistry (Mosc) 81: 1358-1370, 2016.

16. Badal D, Kumar R, Paul M, Dayal D, Bhansali A, Bhadada SK, Kumar R and Sachdeva N: Peripheral blood mononuclear cells of patients with latent autoimmune diabetes secrete higher levels of pro- \& anti-inflammatory cytokines compared to those with type-1 diabetes mellitus following in vitro stimulation with $\beta$-cell autoantigens. Indian J Med Res 145: 767-776, 2017.

17. Yao Y, Wang JB, Xin MM, Li H, Liu B, Wang LL, Wang LQ and Zhao L: Balance between inflammatory and regulatory cytokines in systemic lupus erythematosus. Genet Mol Res 15: 2016.

18. He X, Smeets RL, van Rijssen E, Boots AM, Joosten I and Koenen HJ: Single CD28 stimulation induces stable and polyclonal expansion of human regulatory T cells. Sci Rep 7: 43003, 2017. 
19. Fan MY, Low JS, Tanimine N, Finn KK, Priyadharshini B, Germana SK, Kaech SM and Turka LA: Differential roles of IL-2 signaling in developing versus mature tregs. Cell Rep 25: 1204-1213.e4, 2018

20. Baecher-Allan C, Brown JA, Freeman GJ and Hafler DA: CD4+CD25high regulatory cells in human peripheral blood. J Immunol 167: 1245-1253, 2001.

21. Rubtsov YP, Niec RE, Josefowicz S, Li L, Darce J, Mathis D, Benoist $\mathrm{C}$ and Rudensky AY: Stability of the regulatory $\mathrm{T}$ cell lineage in vivo. Science 329: 1667-1671, 2010.

22. de la Rosa M, Rutz S, Dorninger H and Scheffold A: Interleukin-2 is essential for $\mathrm{CD} 4+\mathrm{CD} 25+$ regulatory $\mathrm{T}$ cell function. Eur J Immunol 34: 2480-2488, 2004.

23. Levine AG, Arvey A, Jin W and Rudensky AY: Continuous requirement for the TCR in regulatory $\mathrm{T}$ cell function. Nat Immunol 15: 1070-1078, 2014

24. Guo H, Zheng M, Zhang K, Yang F, Zhang X, Han Q, Chen ZN and Zhu P: Functional defects in CD4+ CD25high FoxP3+ regulatory cells in ankylosing spondylitis. Sci Rep 6: 37559, 2016.

25. Wells AD, Gudmundsdottir $H$ and Turka LA: Following the fate of individual $\mathrm{T}$ cells throughout activation and clonal expansion. Signals from $\mathrm{T}$ cell receptor and CD28 differentially regulate the induction and duration of a proliferative response. J Clin Invest 100: 3173-3183, 1997.

26. Gudmundsdottir H, Wells AD and Turka LA: Dynamics and requirements of $\mathrm{T}$ cell clonal expansion in vivo at the single-cell level: Effector function is linked to proliferative capacity. J Immunol 162: 5212-5223, 1999.

27. Borsellino G, Kleinewietfeld M, Di Mitri D, Sternjak A, Diamantini A, Giometto R, Höpner S, Centonze D, Bernardi G, Dell'Acqua ML, et al: Expression of ectonucleotidase CD39 by Foxp3+ Treg cells: Hydrolysis of extracellular ATP and immune suppression. Blood 110: 1225-1232, 2007.

28. Fontenot JD, Rasmussen JP, Gavin MA and Rudensky AY: A function for interleukin 2 in Foxp3-expressing regulatory T cells Nat Immunol 6: 1142-1151, 2005.
29. Li X and Zheng Y: Regulatory T cell identity: Formation and maintenance. Trends Immunol 36: 344-353, 2015.

30. Passerini L and Bacchetta R: Forkhead-box-P3 gene transfer in human CD4(+) T conventional cells for the generation of stable and efficient regulatory $\mathrm{T}$ cells, suitable for immune modulatory therapy. Front Immunol 8: 1282, 2017.

31. Ezzelarab MB: Regulatory T cells from allo- to xenotransplantation: Opportunities and challenges. Xenotransplantation 25: e12415, 2018

32. Min B: Heterogeneity and stability in Foxp3+ regulatory T cells. J Interferon Cytokine Res 37: 386-397, 2017.

33. Tanaka T, Narazaki $M$ and Kishimoto T: IL-6 in inflammation, immunity, and disease. Cold Spring Harb Perspect Biol 6: a016295, 2014.

34. Wiesinger M, Stoica D, Roessner S, Lorenz C, Fischer A, Atreya R Neufert CF, Atreya I, Scheffold A, Schuler-Thurner B, et al: Good manufacturing practice-compliant production and lot-release of ex vivo expanded regulatory $\mathrm{T}$ cells as basis for treatment of patients with autoimmune and inflammatory disorders. Front Immunol 8: 1371, 2017.

35. Fletcher JM, Lonergan R, Costelloe L, Kinsella K, Moran B, O'Farrelly C, Tubridy N and Mills KH: CD39+Foxp3+ regulatory $\mathrm{T}$ cells suppress pathogenic Th17 cells and are impaired in multiple sclerosis. J Immunol 183: 7602-7610, 2009.

36. Gu J, Ni X, Pan X, Lu H, Lu Y, Zhao J, Guo Zheng S, Hippen KL, Wang $\mathrm{X}$ and $\mathrm{Lu} \mathrm{L}$ : Human CD39(hi) regulatory T cells present stronger stability and function under inflammatory conditions. Cell Mol Immunol 14: 521-528, 2017. 